\title{
Potencial competitivo de tres mipymes del sector agroindustrial de la provincia de Ubaté, Colombia
}

\author{
Sandra Milena Melo Perdomo ${ }^{1}$ \\ Universidad de Cundinamarca \\ smmelo@ucundinamarca.edu.co \\ Crescencio Orrego ${ }^{2}$ \\ Universidad de Cundinamarca \\ corrego@ucundinamarca.edu.co \\ Ignacio Gómez Roldán ${ }^{3}$ \\ Universidad de Cundinamarca \\ ignacio.gomez19@gmail.com \\ Johanna Andrea Gil Palacios ${ }^{4}$ \\ Universidad de Cundinamarca \\ jandreagil@ucundinamarca.edu.co
} Fecha de recepción: 16 de junio de 2018 Fecha de aprobación: 19 de agosto de 2018

DOI: https://doi.org/10.21158/01208160.n0.2018.2022

Cómo citar este artículo / To reference this article / Comment citer cet article / Para citar este artigo: Melo Perdomo, S. M.; Orrego, C.; Gómez Roldán, I. y Gil Palacios, J. A. (2018). Potencial competitivo de tres mipymes del sector agroindustrial de la provincia de Ubaté. Revista EAN, Edición especial, pp 145-170. DOI: https://doi.org/10.21158/01208160. n0.2018.2022

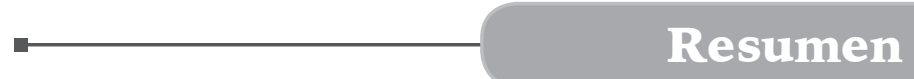

El presente trabajo tiene como objetivo principal estudiar el potencial competitivo de tres empresas del sector agroindustrial de la Provincia de Ubaté, a través de una herramienta que permite hacer este análisis desde una perspectiva endógena. Se describe primero la fundamentación teórica y posteriormente se describe paso a paso el método, cuyo uso fue motivado por la posibilidad de disminuir las dificultades actuales para medir la competitividad de una empresa: necesidad de niveles altos de información de los competidores y la multiplicidad de componentes a calificar en los rankings actuales. Desde una metodología analítico-descriptiva se presentan resultados, cuyo origen requirió análisis cualitativo y cuantitativo, y las conclusiones comparadas validan el modelo en el contexto estudiado y su nivel de replicabilidad a otras empresas del sector.

\section{Palabras Clave}

Agroindustria, competitividad, pymes Ubaté —Cundinamarca, Colombia—, desempeño económico, competencia económica.

\footnotetext{
${ }^{1}$ Magister en Administración de empresas y Dirección de proyectos, Universidad Viña del mar. Especialista en Gerencia y Administración Financiera, Universidad Piloto de Colombia. Ingeniera Financiera, Universidad Piloto de Colombia. ORCID: https://orcid.org/0000-0002-7699-5206

${ }^{2}$ Magister en Educación, Universidad Cooperativa de Colombia. Profesor en Ciencias de la Educación, Universidad Nacional del Nordeste, Rcia. Chaco - Argentina.

${ }^{3}$ Doctor en Análisis Económico UNED. Especialista en Evaluación Social de Proyectos Universidad de los Andes. Magíster

${ }^{4}$ Administradora de Empresas de la Universidad EAN; especialista en Gerencia de Mercadeo de la Universidad Javeriana; candidata a Magíster en Educación de la Universidad de Cundinamarca.
} 


\title{
Competitive potential of three mipymes from the agribusiness sector in the region of Ubate, Colombia
}

\begin{abstract}
This paper aims at studying the competitive potential of three small companies belonging to the agribusiness sector in the region of Ubate, Colombia, by using a tool which allows to make this analysis from an endogenous perspective. First, a theoretical framework is given, and then the method is described following a stepby-step perspective, whose motivation results from the possibility to diminish current difficulties when measuring company competitiveness: a need to reach high levels of information about competitors and the multiplicity of components to determine current rankings. Based on a descriptive- analytical methodology, outcomes are described, whose origin require a quantitative and a qualitative analysis, and the resulting compared outcomes validate the model in the given context as well as the level of duplicability in other companies from the same economic sector.
\end{abstract}

key words: Agribusiness, competitiveness, Ubate PyMES (in Cundinamarca, Colombia), economic development, economic competition

\section{Potentiel compétitif de trois PME du secteur agro-industriel de la province d'Ubaté, Colombie}

Résumé. Cet article a pour objectif principal l'étude du potentiel compétitif de trois entreprises agricoles de la région d'Ubaté grâce à un outil offrant une analyse endogène de cette perspective. Une description des fondements théoriques est réalisée dans un premier temps avant de procéder à une méthode empirique par étape afin de réduire les difficultés actuelles des PME et améliorer leur compétitivité en leur offrant un niveau élevé d'information de la concurrence et les informant de la multiplicité des composants qualificatifs des classements actuels. Les résultats de cette méthodologie analytico-descriptive dont l'obtention a nécessité une analyse qualitative sont ensuite présentés et comparés aux conclusions pour la validation du modèle dans le contexte étudié et son niveau de réplicabilité à d'autres entreprises.

Mots clefs: Agro-industrie, compétitivité, PME Ubate (Cundinamarca, Colombie), performance économique, concurrence économique

\section{Potencial competitivo de três MiPyMEs do sector agroindustrial da Província de Ubaté, Colômbia}

Resumo. O presente trabalho tem como objetivo principal estudar o potencial competitivo de três empresas do setor agroindustrial de a Província de Ubaté, a través de uma ferramenta que permite fazer esta análise desde uma perspectiva endógena. Descreve-se primeiro a fundamentação teórica e posteriormente descreve-se passo a passo o método, cujo uso foi motivado pela possibilidade de diminuir as dificuldades atuais para medir a competitividade de uma empresa: necessidade de níveis altos de informação dos concorrentes e a multiplicidade de componentes a qualificar nos rankings atuais. Desde uma metodologia analítico-descritiva apresentam-se resultados, cuja origem requereu análise qualitativa e quantitativa. As conclusões comparadas validam o modelo no contexto estudado e seu nível de reprodução a outras empresas do setor.

Palavras-chave: Agroindústria, competitividade, MPEs Ubaté (Cundinamarca, Colômbia), desempenho econômico, concorrência econômica. 


\section{Introducción}

T a competitividad es un concepto de Linterés general, tanto para las empresas que han incursionado en mercados desarrollados como para aquellas que aún limitan sus actividades a mercados locales. Cualquier firma hoy en día se enfrenta a retos competitivos de tipo global. Esto se refleja en la multiplicidad de estudios, definiciones y enfoques actuales frente al concepto de competitividad.

La provincia de Ubaté, según la base de datos empresarial de la Cámara de Comercio de Bogotá (s. f.), cuenta actualmente con 3612 empresas inscritas, de las que el 95,4\% corresponden a microempresas, el 3,93\% a empresas pequeñas y tan solo el $0,58 \%$ a empresas medianas. Sepúlveda, Meriño, Del Río y García (2010) proponen un modelo que puede medir el potencial competitivo de las mipymes desde el análisis de sus condiciones internas, que se adapta a los objetivos de la presente investigación, cuyo propósito es medir el potencial competitivo de tres empresas del sector agroindustrial en dicha provincia.

La agricultura es una de sus principales actividades y la agroindustria es identificada como actividad estratégica para los países en desarrollo. La Organización de las Naciones Unidas para la Alimentación y la Agricultura (FAO) manifiesta que la agroindustria desarrollada por pymes desempeña un papel económico vital, además de ser protagonista en el tema de seguridad alimentaria (Becerra Gualdrón y Gallardo Sánchez, 2015).

El grupo de investigación AdCUN tiene como uno de sus focos geográficos de estudio la provincia de Ubaté y como intereses investigativos el impulso de la competitividad y el emprendimiento. Por tanto, a través del semillero Adcun Estudios, indaga en este sector la posibilidad de potenciar todas aquellas oportunidades que puedan tener las empresas para agregar valor a los productos, impulsar su competitividad e incursionar en nuevos mercados. Por ello, se seleccionan tres empresas y se aplica el modelo mencionado, con el fin de validar la posibilidad de analizar sus potenciales competitivos individuales, $y$ con ello evaluar la replicabilidad del modelo a otras firmas.

Para esto, en la primera parte, se establece la fundamentación teórica que aborda las perspectivas internacionales, nacionales $\mathrm{y}$ locales. Luego, se apropia el modelo de medición para evaluar el potencial competitivo describiendo paso a paso las diferentes fases que se requieren para su aplicación. En la tercera parte, se analizan las condiciones internas de tres empresas del sector agroindustrial de la provincia de Ubaté, evaluando sus potenciales competitivos y destacando de manera comparativa los resultados. 


\section{Fundamento teórico}

$\mathbf{L}$ os conceptos que se asocian y aplican a la palabra competitividad son relevantes en los estudios de universidades de gran parte del globo, acuerdos internacionales, regiones, municipios, provincias, industrias y firmas. Su frecuente uso en los estudios económicos y de negocios conduce a una preocupación sobre la ambigüedad de tales definiciones, puesto que obstaculizan la medición y comparación de la competitividad. De tal manera que suelen usarse indicadores compuestos con el objeto de medirla. Sin embargo, los resultados comparativos son imperfectos, utilizándose frecuentemente diferentes indicadores o variables para medirla (Sepúlveda et al., 2010).

El término viene de la palabra clásica latina petere, cuyo significado es apuntar, desear, buscar, atacar, y del prefijo del latín con que significa juntos. Actualmente, la palabra es usada en diferentes contextos dándole distintos significados. Entre las varias definiciones que se han dado por los teóricos se pueden mencionar las siguientes:

La capacidad que tienen las naciones, regiones y empresas para generar riqueza constituyéndose en requisito para el logro de salarios altos (Bobba, Langer y Pous, 1971). Es también entendida como la capacidad de los sectores, las industrias o las ramas para diseñar y vender productos con precios y calidad más atractivos que los competidores (Flejterski, 1984). En la misma dirección, también se entiende como la capacidad de un país para crear, producir, distribuir y dar servicios a los productos en el comercio internacional obteniendo rendimientos crecientes (Scott y Lodge, 1985). Refiriéndose al mismo término, es claro que los diferentes autores toman aspectos relacionados, diferentes y complementarios.
En el ámbito de las empresas, la competitividad es la capacidad para producir y vender productos y servicios de superior calidad a menores costos que los competidores nacionales y foráneos, brindando rendimientos de largo plazo a las firmas, suministrando mayores compensaciones a sus trabajadores y mayores ganancias a los accionistas (Buckley, Pass y Prescott, 1988). Se añade que la competitividad a nivel nacional requiere crecimientos en la productividad del país para aumentar su calidad de vida con empleo y sostenibilidad (Porter, 1990). Esta es otra manera de expresar la competitividad como productividad, recalcando que el crecimiento de las capacidades de los países es necesario para mejorar su nivel de vida, teniendo en cuenta que este concepto no tiene sentido cuando se aplica solo a las economías nacionales (Krugman, 1990, 1994). Esta posición reclama pasar la prueba de la competencia internacional con aumentos en los niveles de vida sostenible (D'Andrea Tyson, 1992) y crece entre los economistas cuando de discusiones sobre competitividad se trata.

La Comisión Económica para América Latina y el Caribe (Cepal) introduce una definición estructural de competitividad, en busca de igualdad social y satisfacer las necesidades propias de las economías en desarrollo. Aquí subyace entonces el concepto de competitividad auténtica, entendida como «la capacidad de una economía de sostener e incrementar el nivel de participación en los mercados internacionales, [...] [con] la incorporación del progreso tecnológico en simultánea con un alza en el nivel de vida de la población» (1990, p. 70).

La Organización de Cooperación y Desarrollo Económico (OCDE, 1992) propuso el concepto de competitividad estructural, que vincula la 
capacidad de activar el aprendizaje y la inventiva en todos los niveles de la organización, convirtiendo a la innovación en factor fundamental de sostenibilidad y desarrollo. Así mismo, el concepto integrador de competitividad sistémica con cuatro niveles: meso, micro, macro y meta complementa y estructura las dimensiones de análisis que incluye el diálogo de la sociología industrial y la toma conjunta de decisiones con el involucramiento de todos los actores (Esser, Wolfgang, Dirk y Meyer-Stamer, 1996).

Desde una perspectiva de la gestión administrativa dinámica y estratégica, Porter (1999) introduce el término de ventaja competitiva generadora de valor, y reconoce las condiciones necesarias de liderazgo sostenible a largo plazo, mediante la creación de factores diferenciadores con impactos en la gestión de costos. En otras palabras, o se tiene la capacidad de ofrecer productos y servicios a menor precio o se introducen características diferenciadoras en el mercado que sean claramente percibidas y valoradas por los consumidores, y por las que los consumidores están incluso dispuestos a pagar un mayor precio. Así, la competitividad se entiende como un factor de las unidades productivas y su consecución, un tema estratégico de gestión administrativa. Aduciendo que la competitividad se deriva de una mayor productividad acompañada con menores costos frente a sus rivales nacionales o internacionales, se deben ofrecer productos y servicios con mayor valor agregado que los demás oferentes (Romo y Abdel, 2005). Así mismo, «la competitividad de la empresa es el resultado de una gerencia exitosa, también es necesario que el entorno empresarial contribuya a esa competitividad» (Suñol, 2006, p. 182).

La competitividad se evidencia al producirse bienes y servicios probados en los mercados internacionales, pudiéndose simultáneamente mantener y aumentar los ingresos reales de la población a largo plazo (Barker y Köhler , 1998).
La competitividad es un concepto dinámico, que se transforma en el tiempo, y lo que antes la condicionaba no necesariamente lo hace siempre. Puede perder vigencia en la medida en que surgen fenómenos como la profundización de la globalización y las dinámicas cambiantes de las empresas, sus contextos y la población. Por tanto, en el estudio de la competitividad, conviene analizar permanentemente los factores internos y externos de las organizaciones.

Desde la mirada pragmática e intuitiva de otros autores, se la define o evidencia entonces con el fogueo en los mercados mundiales, de modo que son los beneficios un juego de suma cero, ya que las ganancias de un país se dan a expensas de los demás (Porter, Ketels y Delgado, 2007).

Desde miradas de los agentes individuales, se señaló que son las firmas y no las naciones las que realmente compiten en los mercados internacionales (Porter, 1990). La competitividad de la empresa yace en su fortaleza económica en franca lid con sus rivales del mercado global, en el que, a pesar de la existencia de las fronteras, se hacen movimientos libres de servicios, personas, productos e innovaciones (Wang y Hsu, 2010), que contrastan con otras definiciones más incluyentes, o si se quiere, más globales. Así también se le define como el conjunto de instituciones, políticas y factores que determinan el nivel de productividad de un país (Schwab y Sala-i Martin, 2013). De tal manera que el término se explica, mayormente, con las capacidades o condiciones de las empresas.

Dado todo lo anterior entonces la competitividad es concebida como un concepto relativo y multidimensional asociada con el mercado. La complejidad del término o fenómeno yace en su vínculo con muchas variables que sugieren la conveniencia de referirse a las varias características comparables. De tal manera que los 
varios conceptos asociados y teorías de la competitividad se refieren a grupos de países o a naciones desde unas perspectivas macro, hasta la mirada puesta en variables microeconómicas en las empresas.

El estudio de los sectores sobre los que se hacen los análisis son referentes de la competitividad de las empresas, incluye, entre otros, su sentido de sostenibilidad y desarrollo, lo que exige resultados positivos desde el punto de vista de la eficiencia y remuneración de los accionistas.

Aun cuando una multitud de factores - que incluye las condiciones climáticas y los ciclos de negocios- pueden afectar la rentabilidad de un sector en el corto plazo, es la estructura del sector, la cual se manifiesta en las fuerzas competitivas, la que determina la rentabilidad del sector en el mediano y largo plazo. (Porter, 2008, pp. 2-3)

Este autor propone cinco fuerzas que dan forma a la competencia del sector: a) amenaza de entrada de nuevos competidores, b) amenaza de productos o servicios sustitutos, c) poder de negociación de los proveedores, d) poder de negociación con la competencia y e) rivalidad entre los competidores existentes.

Frente a Porter, en el modelo de las cinco fuerzas, propone un análisis sectorial con consideraciones del entorno, así el presente trabajo se enfoca en la dimensión interna de las organizaciones. Aquí se propone la aplicación de un modelo en condiciones de autonomía empresarial en el análisis del perfil competitivo. En este sentido, Guerras y Navas (2015) expresan la importancia que se le debe conceder al estudio de los recursos y las capacidades internas «como teoría explicativa de las razones por las que distintas empresas que actúan en la misma industria presentan ventajas competitivas diferentes» (p. 26).

Dependiendo del objeto de estudio, los académicos acuden a variaciones en los determinantes de la competitividad, y es conveniente ser preciso en las explicaciones de cada caso, puesto que los malos entendidos traen consecuencias no deseadas en los discursos políticos como en las decisiones políticas y corporativas (Porter y Rivkin, 2012).

Para la visión gubernamental colombiana, la definición de competitividad cuenta con múltiples aristas:

La competitividad de una nación se define como el grado en el que un país puede producir bienes y servicios capaces de competir exitosamente en mercados globalizados y a la vez mejorar las condiciones de ingreso y calidad de vida de su población. [...] es el resultado de la interacción de múltiples factores relacionados con las condiciones que enfrenta la actividad empresarial y que condicionan su desempeño, tales como infraestructura, recursos humanos, ciencia y tecnología, instituciones, entorno macroeconómico, y productividad. (Conpes 3439/2006, 14 de agosto)

La política actual está enmarcada en lo descrito en la Agenda Nacional de Competitividad e Innovación 2014-2018, cuyo plan inmediato para respaldar los desafíos de la transformación productiva está enfocada en la transformación industrial. 


\section{Antecedentes contextuales de competitividad de Colombia y Cundinamarca}

Según el Consejo Privado de Competiti-
vidad:

En el Índice Global de Competitividad (IGC) del Foro Económico Mundial (WEF), por ejemplo, Colombia pasó del puesto 63 entre 122 países en 2006 al puesto 61 entre 138 en 2016. Así mismo, en el ranking del Doing Business del Banco Mundial pasó del puesto 76 en 2006 al 54 en 2016. Solo desmejoró en el Anuario de Competitividad Mundial del Institute for Management Development (IMD) —que se concentra en las 61 economías de mayor nivel de desarrollo-, al pasar del puesto 40 en 2006 al 51 en 2016 [...] En el IGC del WEF Colombia aún ocupa el quinto puesto en Latinoamérica. (2016a, p. 12)

En el transcurso de diez años durante los que se ha dado una recesión mundial, se dio un pequeño escalamiento en el ranking, aunque el número de países aumentó el $13 \%$. Mientras que en otro ranking, incrementó 22 puestos, disminuyó en el del Institute for Management Development (IMD) en 11.
El país tiene que hacer una apuesta nacional por la competitividad en la que academia, gobiernos, empresarios y sociedad civil deben articularse para superar las limitaciones económicas que frenan un mayor bienestar. A pesar de haber avanzado en la dirección correcta, en particular, en el mercado financiero, se requieren mayores esfuerzos conjuntos para ganar, acelerar y profundizar la competitividad. La construcción de la paz ofrece unas oportunidades de coordinación para generar ciclos virtuosos de crecimiento.

En el ranking departamental de competitividad de 2016 (tabla 1), Cundinamarca ocupa el sexto lugar, con puntaje de 5,44, mientras el mayor lo tiene Bogotá, con 8,18, habiendo obtenido el séptimo en 2014. Participa con el 5,06 \% del PIB y tiene una población estimada de 2,72 millones de habitantes. Su mejor posición en el ranking es el cuarto lugar en los pilares de tamaño del mercado, y en innovación y en sofisticación. Sus peores posiciones en el ranking son el puesto 14 en salud, y el puesto 10 en infraestructura (Consejo Privado de Competitividad, 2016b, p. 72)

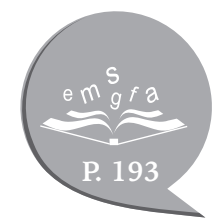


Tabla 1. Índices de competitividad del departamento de Cundinamarca

\begin{tabular}{|l|c|c|}
\cline { 2 - 3 } \multicolumn{1}{c|}{} & Puntaje (0-10) & Posición (entre 26) \\
\hline Índice Departamental de Competitividad 2016 & 5,44 & 6 \\
\hline Condiciones básicas (30 \%) & 5,97 & \multicolumn{2}{|c|}{10} \\
\hline Instituciones & 6,60 & 4 \\
\hline Infraestructura & 4,77 & 5 \\
\hline Tamaño del mercado & 7,61 & 14 \\
\hline Educación básica y media & 6,40 & 7 \\
\hline Salud & 4,98 & 7 \\
\hline Sostenibilidad ambiental & 6,61 & 8 \\
\hline Eficiencia (50 \%) & 5,00 & 5 \\
\hline Educación superior y capacitación & 4,98 & 4 \\
\hline Eficiencia de los mercados & 5,02 & 4 \\
\hline Sofisticación e innovación (20 \%) & 5,72 & 7 \\
\hline Sofisticación y diversificación & 8,16 & 3,28 \\
\hline Innovación y dinámica empresarial & & \\
\hline
\end{tabular}

\section{Fuente. Consejo Privado de Competitividad, 2016a.}

En dinámica empresarial, el departamento ocupa un cuarto lugar, y al examinar la densidad empresarial y la tasa neta de natalidad empresarial (tabla 2), la situación no es halagüeña, pues los puntajes son muy bajos. En tales condiciones, es mucho lo que hay que profundizar desde el punto de vista de la investigación empresarial, que permita allanar caminos para aumentar la condición competitiva de las empresas del departamento, aún más, de las empresas de carácter agroindustrial de la provincia de Ubaté que son sustento importante de la actividad económica de la región. 
Tabla 2. Discriminación de dos pilares del índice de competitividad de Cundinamarca: sofisticación y diversificación, innovación y dinámica empresarial

\begin{tabular}{|c|c|c|c|}
\hline & \multirow{3}{*}{$\begin{array}{c}\text { Puntaje (0-18) } \\
8,16\end{array}$} & \multirow{3}{*}{$\frac{\text { Posición (entre 26) }}{4}$} \\
\hline & & & \\
\hline & Sofisticación y diversificación & & \\
\hline SOF-1 & Sofisticación & 6,67 & 4 \\
\hline SOF-1-1 & Complejidad del aparato productivo & 6,67 & 4 \\
\hline SOF-2 & Diversificación & 9,65 & 5 \\
\hline SOF-2-1 & Diversificación de mercados de destinos de exportaciones & 9,58 & 7 \\
\hline \multirow[t]{2}{*}{ SOF-2-2 } & Diversificación de la canasta exportadora & 9,73 & 3 \\
\hline & Innovación y dinámica empresarial & 3,28 & 7 \\
\hline INN-1 & Investigación & 0,99 & 15 \\
\hline INN-1-1 & Investigación de alta calidad & 1,11 & 15 \\
\hline INN-1-2 & Revistas indexadas & 0,88 & 16 \\
\hline INN-2 & Inversión en CTI y patentes & 2,79 & 5 \\
\hline INN-2-1 & Inversión en ACTI & 3,77 & 4 \\
\hline INN-2-2 & Patentes y diseños industriales & 1,81 & 7 \\
\hline INN-3 & Dinámica empresarial & 4,91 & 4 \\
\hline INN-3-1 & Tasa de natalidad empresarial neta & 2,99 & 9 \\
\hline INN-3-2 & Densidad empresarial & 1,73 & 11 \\
\hline INN-3-3 & Participación de medianas y grandes empresas & 10,00 & 1 \\
\hline
\end{tabular}

CTI: ciencia, tecnología e innovación; ACTI: actividades de ciencia, tecnología e innovación.

Fuente. Consejo Privado de Competitividad, 2016a.

La provincia de Ubaté tiene 1408 km2, que corresponden al 6,2\% del área total del departamento de Cundinamarca, séptima en tamaño.

En la región se registran numerosas migraciones de personas, en su mayoría jóvenes en busca de mejores oportunidades (principalmente hacia Bogotá). Lo anterior confirma el reto que enfrenta la provincia de Ubaté respecto a la formulación de una age nda de proyectos económicos que, además de crear dinámicas de generación de valor, brinden oportunidades laborales de calidad para sus habitantes. La población de la provincia de Ubaté está concentrada en el área rural -59 \%-. (Cámara de Comercio de Bogotá, 2013, pp. 13-14)
El PIB de la provincia de Ubaté tiene mayoritaria participación agropecuaria $(21,7 \%)$. La minería representa el 6,3\%, y las manufacturas vinculadas a la agroindustria y a la transformación de minerales el 12,3\%, mientras que la Administración pública representa el $23 \%$ (Cámara de Comercio de Bogotá, 2013, pp. 17-18).

La explotación bovina es la más importante de las actividades pecuarias de la provincia de Ubaté. Cuenta con más de 102000 cabezas (7,9 \% del departamento). «La mayor parte del inventario $(67,5 \%)$ está dedicado a la producción de leche - uno de los principales motores de la economía regional-, mientras que para la explotación con doble propósito y la producción de carne se destinan el 20,2 \% y el 
$12,3 \%$ del total de bovinos, respectivamente» (Cámara de Comercio de Bogotá, 2013, p. 27).

Las mayores oportunidades de la provincia de Ubaté radican en su conexión directa con importantes corredores viales del orden nacional, aumento del interés por generar valor a los principales productos agrícolas de la región -papa, arveja y maíz-y a los derivados lácteos. Las amenazas se enfocan en la competencia con otras provincias por el mercado de productos agroindustriales, los tratados de libre comercio y la alta vulnerabilidad al cambio climático (Cámara de Comercio de Bogotá, 2013, pp. 49-50).

\section{Apropiación del modelo de medición de competitividad y evaluación de competitividad de empresas agroindustriales}

Se aplica la metodología de evaluación desarrollada por Sepúlveda et al. (2010), en la que se mide el potencial competitivo de las empresas sin la necesidad de recurrir a comparaciones intersectoriales. Esta investigación se desarrolló siguiendo las siguientes etapas: primero, reconocimiento de las categorías de análisis; segundo, medición cualitativa de los factores empresariales vinculados a cada categoría de análisis; y tercero, determinación de análisis gráfico multidimensional a partir de la medición cualitativa de la segunda etapa.

Las categorías de análisis fueron establecidas por Sepúlveda et al. (2010), a partir de un estudio cienciométrico realizado a 148 artículos científicos relacionados con el tema de competitividad. Los autores del modelo listaron los términos claves que coincidían en todos ellos y determinaron las intersecciones conceptuales con ayuda de algoritmos de mapas SOM. ${ }^{6} \mathrm{~A}$ través de mapas de concurrencias, es decir, palabras que aparecen de manera grupal en

\footnotetext{
${ }^{5}$ Los autores del modelo utilizan el término componentes, pero los autores de este artículo consideran más apropiado el término categorías de análisis.

${ }^{6}$ Mapas SOM, mapa autoorganizado, tipo red neuronal artificial.
} 
varios de los artículos analizados, los autores determinaron los términos más repetidos a la hora de hablar de competitividad. En este análisis, se estandarizaron, a través del análisis de puntos convergentes, las categorías de análisis utilizadas en esta investigación del grupo de empresas del sector agroindustrial de Ubaté.

Para reconocer las categorías de análisis propuestas, se utilizaron otros modelos para medir competitividad en pymes, tras lo cual se encontró, por un lado, coincidencias del estudio cienciométrico con el análisis de Rubio y Aragón (2006), quienes analizaron los factores competitivos que explican el éxito en una pyme, y el número de autores que han citado cada una de las categorías. Por otro lado, también se encontraron puntos coincidentes con los análisis de Solleiro y Castañón (2005), quienes tomaron los factores internos empresariales que facilitan la innovación y la competitividad. Esta comparación puede observarse en la tabla comparativa de estos tres modelos (tabla 3 ).

Tabla 3. Comparativo entre modelos de las categorías de análisis para medir las capacidades competitivas de una empresa

\begin{tabular}{|l|l|l|}
\hline Sepúlveda et al. (2010) & Rubio y Aragón (2006) & $\begin{array}{l}\text { Solleiro y Castañón } \\
(\mathbf{2 0 0 5})\end{array}$ \\
\hline Infraestructura (física y tecnológica) & Recursos tecnológicos & Tecnología \\
\hline Evaluación financiera & Gestión financiera & Recursos financieros \\
\hline I+D & Innovación & I+D \\
\hline Satisfacción al cliente & Recursos comerciales y capacidades de marketing & Mercadotecnia \\
\hline Toma de decisiones & Capacidades directivas & \\
\hline Planeación estratégica y talento humano & Recursos humanos & Recursos humanos \\
\hline Vigilancia o análisis del entorno & & \\
\hline Posicionamiento & & Calidad \\
\hline (Incluido en satisfacción al cliente) & Calidad & \\
\hline & Valores culturales & \\
\hline
\end{tabular}

Fuente. Elaboración propia según Sepúlveda et al., 2010.

Definidas las categorías, se hizo el análisis cualitativo utilizando la escala de Likert calificando con números enteros de 1 a 5 el grado de desarrollo óptimo de las variables (tabla 4). La aplicación del modelo a las empresas del sector agroindustrial de la provincia de Ubaté se llevó a cabo a través de visitas empresariales con un proceso participativo de gerentes o administradores de la empresa.

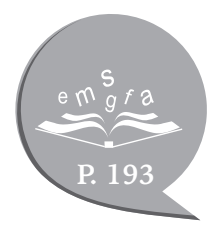


Tabla 4. Criterios para análisis cualitativo en cada categoría de análisis

\begin{tabular}{|c|c|c|c|c|c|}
\hline $\begin{array}{l}\text { Categoría de } \\
\text { análisis }\end{array}$ & $\begin{array}{c}\text { Variables } \\
\text { involucradas }\end{array}$ & $\begin{array}{l}\text { Categoría de } \\
\text { análisis }\end{array}$ & $\begin{array}{l}\text { Variables } \\
\text { involucradas }\end{array}$ & $\begin{array}{l}\text { Categoría de } \\
\text { análisis }\end{array}$ & $\begin{array}{l}\text { Variables } \\
\text { involucradas }\end{array}$ \\
\hline \multirow{4}{*}{ Vigilancia } & Búsqueda & \multirow{4}{*}{ Evaluación financiera } & Métodos & \multirow{4}{*}{$\begin{array}{l}\text { Satisfacción del } \\
\text { cliente }\end{array}$} & Mercadeo \\
\hline & Análisis & & Enfoque & & Servicios \\
\hline & Fuente & & Seguimiento & & Calidad \\
\hline & Conocimiento & & Finanzas & & \\
\hline \multirow{5}{*}{$\begin{array}{l}\text { Toma de } \\
\text { decisiones }\end{array}$} & Bases (técnicas) & \multirow{5}{*}{ Posicionamiento } & Liderazgo & \multirow{5}{*}{ Infraestructura } & Política \\
\hline & Claves & & Logística & & Beneficios \\
\hline & Experiencia & & Valor & & Condicionamiento \\
\hline & & & Personal & & Aprovechamiento \\
\hline & Propiedad & & Globalización & & Mejoras \\
\hline \multirow{6}{*}{$\mathrm{I}+\mathrm{D}$} & Capital & \multirow{6}{*}{ Planeación estratégica } & Recursos & & \\
\hline & Objetivos & & Sistema & & \\
\hline & Encadenamiento & & Organización & & \\
\hline & Capacidades & & Misión & & \\
\hline & TIC & & Visión & & \\
\hline & & & Cambio & & \\
\hline
\end{tabular}

Fuente. Elaboración propia según Sepúlveda et al., 2010.

Los resultados de las calificaciones de cada una de las 73 variables son graficados en diagramas radiales en cada una de las 8 categorías de análisis. Esto permite hacer interpretaciones multidimensionales, en el entendido de que estas se derivan de las variables de cada categoría. Por ejemplo, en la categoría Vigilancia, el diagrama radial resultado tendrá cuatro vértices: búsqueda, análisis, fuente y conocimiento. Cada diagrama radial tiene diferente número de vértices, de acuerdo con las variables involucradas.
El modelo gráfico utilizado define las categorías de análisis, como se ve en la figura 1, correspondiendo un gráfico a cada categoría. Así mismo, en cada vértice se encuentra una variable que favorece la competitividad, cuantificada de acuerdo con el análisis cualitativo llevado a cabo en cada empresa. En la figura del ejemplo, se tienen dos empresas: la primera, denominada «Óptimo» -representada por la línea continua-, describe unas puntuaciones ideales de cinco que representan la máxima competitividad en todas las variables de la categoría en cuestión, abarcando toda el área del rombo. 
Figura 1. Categoría de análisis

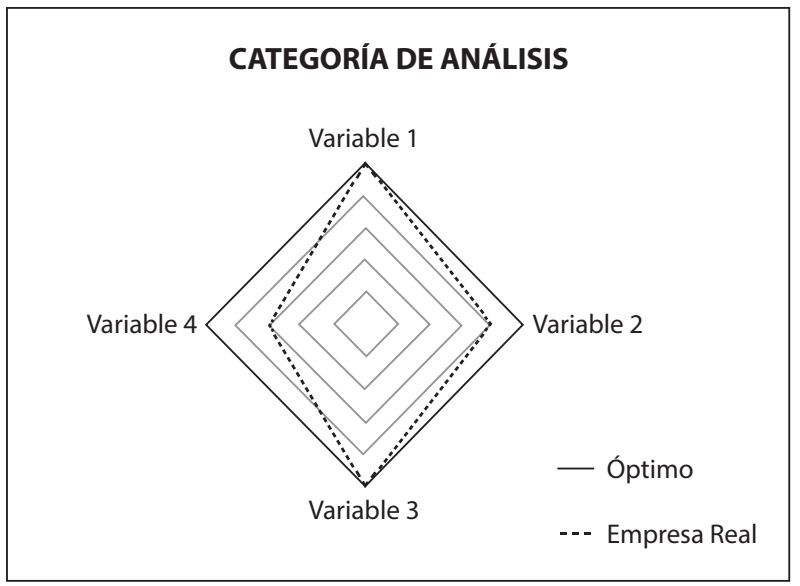

Fuente. Elaboración propia.

En la segunda firma del ejemplo denominada «Empresa real»-representada por la línea punteada-, se muestra que tan solo alcanzó las condiciones ideales de competitividad en las variables 1 y 3 , mientras que en la variable 4 tuvo una puntuación de 3 , que es inferior a la variable de competitividad 2, que alcanzó una puntuación de 4 . De tal manera que la figura representa diferentes empresas en condiciones de competitividad distintas en cada variable, para cada una de las categorías estudiadas.

Los gráficos radiales permiten realizar el análisis cuantitativo al comparar el área total del gráfico -que corresponde al estado ideal de competitividad de cada categoría de análisis-, con el área del perímetro sombreado obtenido en la gráfica de cada uno de las categorías evaluadas. Permite establecer «qué tan lejos» está el producto del estado óptimo o ideal en cada categoría de análisis. Volviendo al ejemplo, el área de la empresa «Óptimo» representa el porcentaje de cumplimiento del $100 \%$ y el área de la «Empresa real» representa el porcentaje de cumplimiento del $70 \% .^{7}$ Esto es que, de acuerdo con las percepciones del análisis cualitativo de las personas de la empresa, la competitividad en esta categoría puede mejorar en el $30 \%$.

El estudio de Rodríguez, Rodríguez y Melo (2017) usando criterios de participación en el mercado y de probabilidad de crecimiento identificó que la canasta de productos agroindustriales más competitivos de la provincia de Ubaté está conformada por queso, menta deshidratada y papa -lavada y empacada-. Para que un producto posea atributos diferenciadores o exclusivos en su estructura de costos, presentación o precio, se requiere una estructura empresarial que los favorezca. En esta dirección, se escogió medir el potencial competitivo de las empresas que los producen, a través del modelo de Sepúlveda et al. (2010) para que se evalúe la pertinencia del uso del modelo en otras empresas de la región. Las empresas seleccionadas tienen características similares a las del promedio de empresas de la provincia, de tal manera que esta primera aproximación, exitosa por cierto, demostró que se puede extender el modelo a otras firmas del sector agroindustrial de la provincia de Ubaté.

\footnotetext{
Se determina sumando las áreas de los triángulos internos resultantes.
} 
A efectos de esta investigación, y reservando el derecho de privacidad de la información manifestada por las empresas evaluadas, se construyó la matriz con unas etiquetas genéricas para no usar el nombre original de las empresas. Para el caso de la empresa dedicada a la producción de quesos se le denominó UNIPROD $1 ;{ }^{8}$ la empresa dedicada a la deshidratación de hierbas aromáticas, específicamente menta para este estudio, se catalogó como UNIPROD2; ${ }^{9}$ y la empresa dedicada a comercializar la papa lavada y empacada, se catalogó como UNIPROD3. ${ }^{10}$

\section{Aplicación del modelo}

-

$\mathbf{L}$

a aplicación del modelo a las empresas UNIPROD1, UNIPROD2 y UNIPROD3 se documenta de manera cualitativa y cuantitativa, para determinar su potencial competitivo. La descripción detallada de las variables de cada vértice en todas las categorías se encuentra en el anexo A. Se debe tener presente la descripción hecha en los pies de página.

\subsection{Análisis cualitativo}

La evaluación de cada una de las categorías de análisis se representa por gráficos radiales que describen los resultados de las tres empresas, para exponer comparativamente conclusiones intersectoriales, divergencias y similitudes.
La categoría Vigilancia presenta coincidencias para las empresas UNIPROD1 y UNIPROD3 en tres de las cuatro variables de análisis. De manera que se obtiene un gráfico superpuesto para las dos empresas, con diferencia únicamente en la variable Fuente. La empresa UNIPROD2 tiene un área mayor en su gráfico, pues todas sus variables presentaron calificación superior frente a las otras dos empresas (figura 2). Esta empresa es más consciente de la necesidad de búsqueda de información de su entorno, y de conocer su competencia. Sin embargo, las tres firmas manifiestan no tener personal dedicado explícitamente a esta labor.

${ }^{8}$ Empresa pequeña dedicada a la comercialización de leche y derivados lácteos, de administración familiar y de más de veinte años de funcionamiento. Actualmente, cuenta con una planta de doce colaboradores.

9 Empresa mediana dedicada a la exportación de hierbas aromáticas deshidratadas y producidas de manera orgánica, constituida desde 2003.

${ }^{10}$ Microempresa familiar dedicada a la comercialización de papa lavada y empacada, con más de veinticinco años de experiencia en producción de papa. Actualmente, cuenta con una planta fija de seis colaboradores. 
Figura 2. Categoría Vigilancia

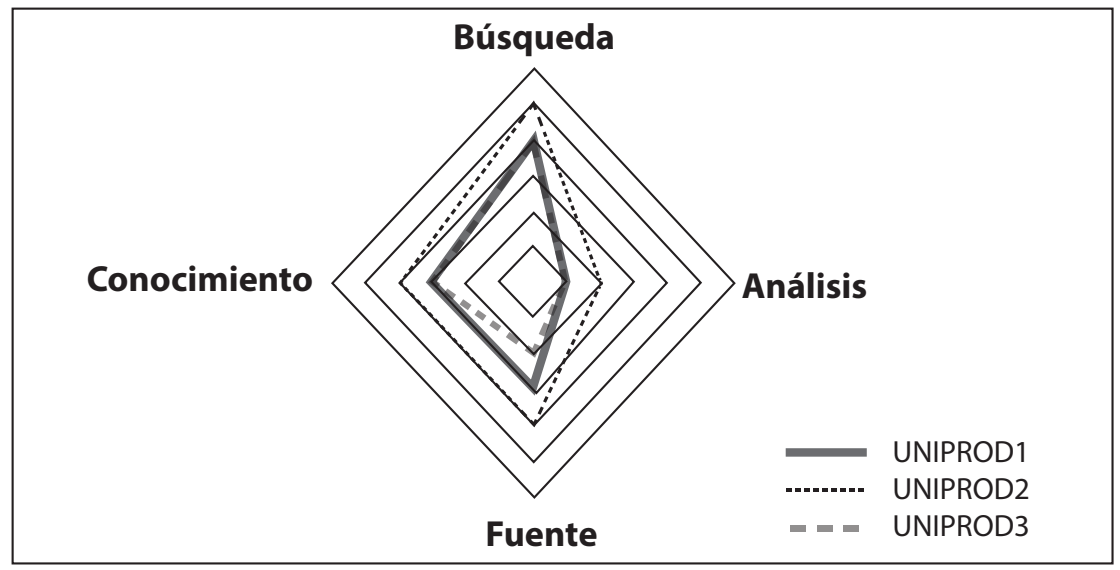

Fuente. Elaboración propia.

Para el caso de la categoría Toma de decisiones, que analiza cuatro variables, también se presenta comportamiento similar para las empresas UNIPROD1 y UNIPROD3, presentando esta última menor desarrollo en las políticas y técnicas que se tienen en la organización para tomar decisiones. La empresa UNIPROD2 no presenta calificación perfecta en la disponibilidad de información técnica a partir de la cual se toman las decisiones, pero evalúa periódicamente su actuar, y tiene claro cada miembro de su organización, su papel a la hora de decidir (figura 3).

Figura 3. Categoría Toma de decisiones

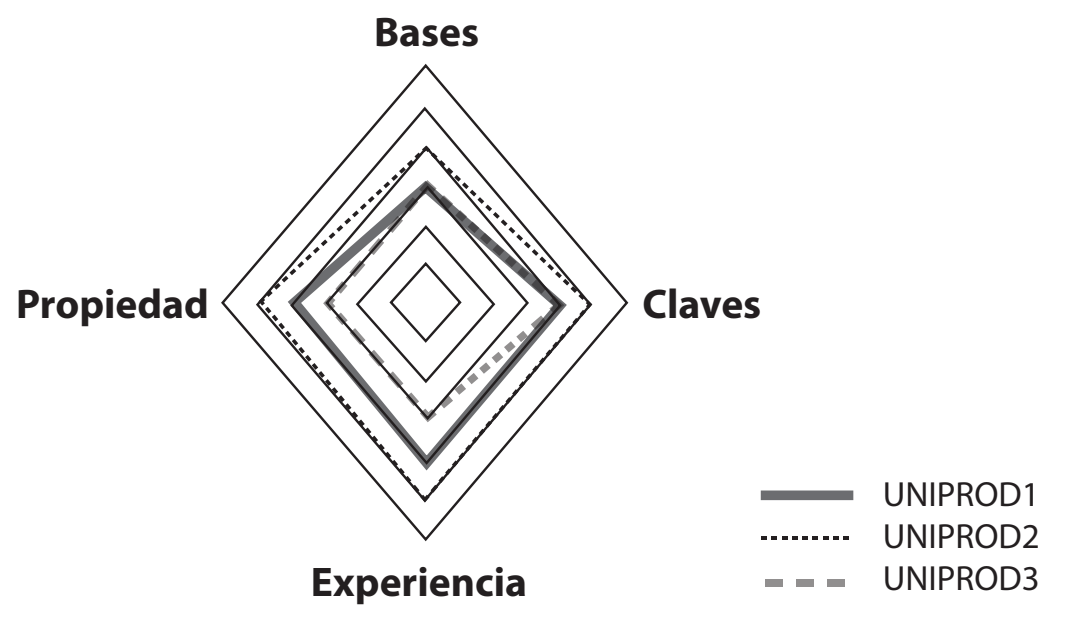

Fuente. Elaboración propia. 
La Infraestructura, y sus cinco variables, presentan comportamientos diferentes en las tres empresas, y refleja la realidad sectorial. En las empresas que producen derivados lácteos, la política es adquirir maquinaria y tecnología que aumente la productividad y favorezca el crecimiento de la capacidad instalada, como lo refleja la empresa UNIPROD1. Los aspectos diferenciadores de los productos que exporta la empresa UNIPROD2 se evidencian en sus políticas tecnológicas, y demuestran que son conscientes de ello. La empresa UNIPROD3, en cambio, evidencia poco desarrollo en este aspecto, justificado por su bajo nivel de transformación del producto, lo que les ha exigido históricamente menor inversión en maquinaria y tecnología, pues la que tienen satisface sus necesidades actuales. Dicho nivel de «conformismo» se refleja en un atraso respecto del potencial competitivo relacionado con esta categoría de análisis y de la comparación con las otras dos empresas (figura 4).

Figura 4. Categoría Infraestructura

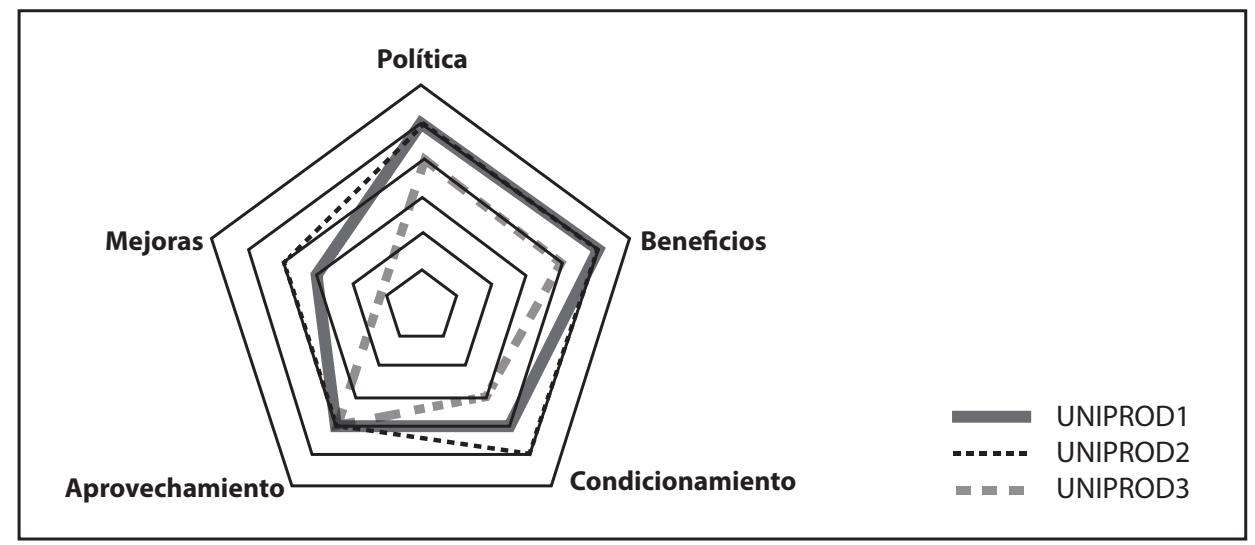

Fuente. Elaboración propia.

I $+\mathrm{D}$ ha sido de los más cuestionados en el ámbito empresarial actual, pues se considera que es la clave de la innovación, el crecimiento y la diferenciación, entre otros aspectos competitivos. Las empresas UNIPROD1 y
UNIPROD2 consideran que han realizado inversiones importantes en este campo y que se evalúa periódicamente el aprovechamiento de las oportunidades y los cambios en los productos (figura 5). 
Figura 5. Categoría I+D

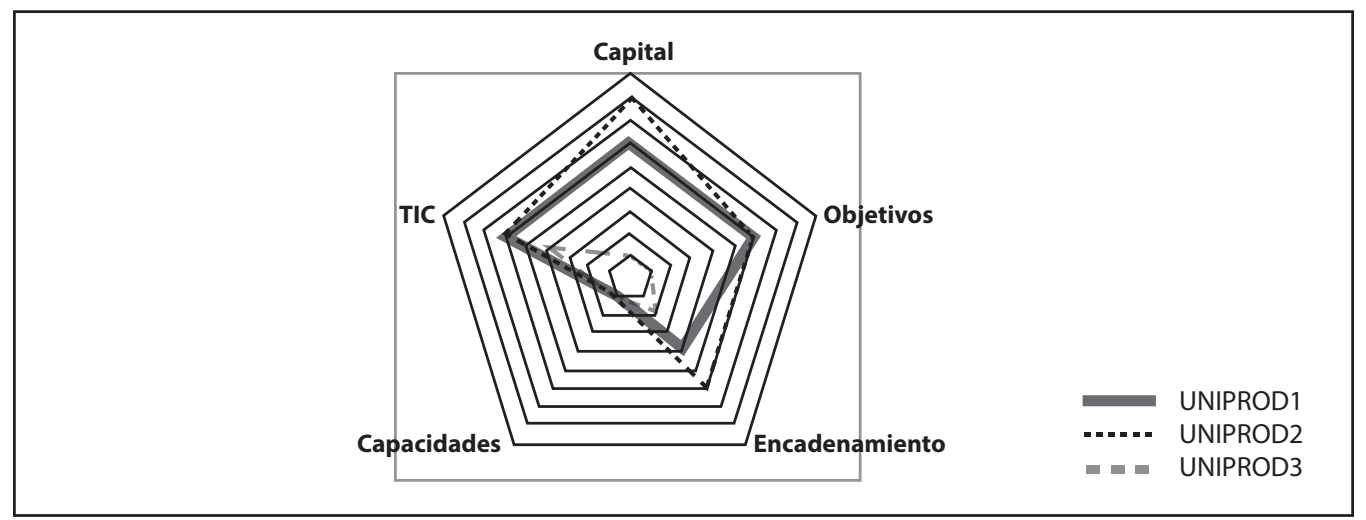

Fuente. Elaboración propia.

Existe bajo desarrollo en las capacidades de mejoramiento de productos o generación de nuevos. Además, no se tiene una política clara para los aportes de los colaboradores en I+D. La empresa UNIPROD3 es la más lejana del potencial competitivo ideal al manifestar en esta categoría que lo único con grado aceptable de desarrollo es la vinculación de las TIC a los diferentes procesos de la organización. De aquí que esta empresa tiene mucho más campo de acción, si de tomar acciones se trata, en políticas de I+D. Al hablar de estrategia y de políticas empresariales, Porter señala que los asuntos de las TIC tienen que ver más con las renovaciones tecnológicas, que las empresas deben hacer so pena de ser castigadas fuertemente por el mercado, que con el diseño y la ejecución de estrategias o políticas empresariales.
La Evaluación financiera es fundamental para la sostenibilidad de cualquier organización. Las empresas UNIPROD1 y UNIPROD2 realizan seguimiento constante a su información financiera y poseen un historial de resultados positivos. Sin embargo, muestran deficiencias en el uso de la información financiera como herramienta para la toma de decisiones -por eso la calificación más baja en la variable Enfoque-. Por su parte, la empresa UNIPROD3 únicamente argumenta resultados financieros positivos; pero, analizando integralmente esta categoría, presenta potencial competitivo con grado de desarrollo muy inferior al de las otras empresas analizadas. Hay mucho por hacer en temas de seguimiento y uso de la información para diagnosticar y tomar decisiones (figura 6). 
Figura 6. Categoría Evaluación financiera

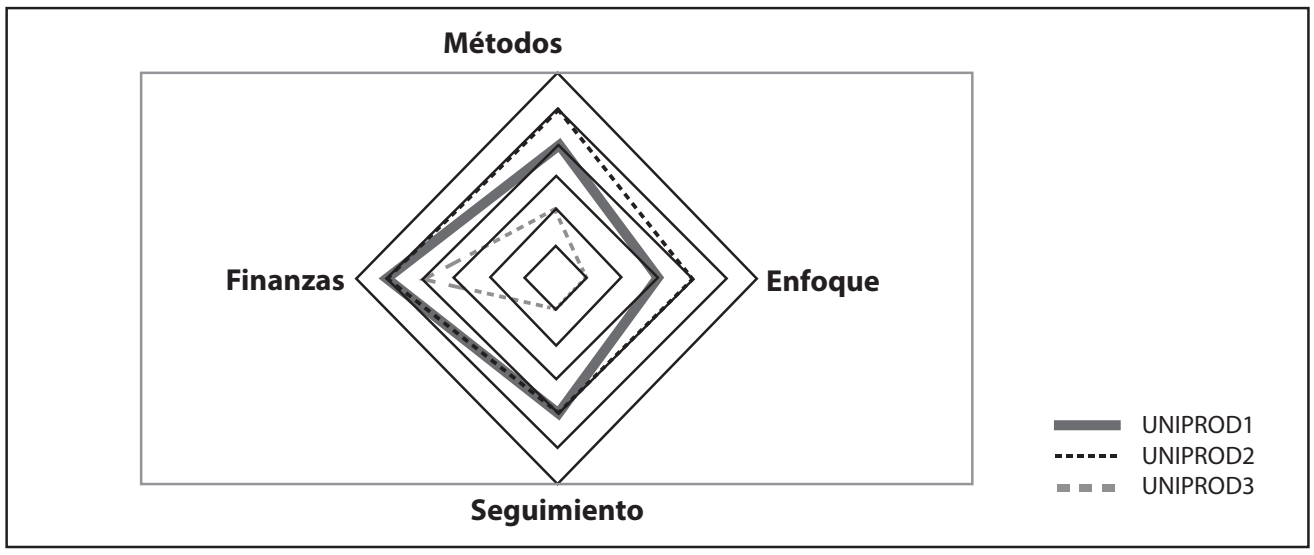

Fuente. Elaboración propia.

La categoría Posicionamiento estudiada en la figura 7 muestra el rezago de la empresa UNIPROD3 en el grado de desarrollo, reconociendo la ausencia de tres de las cinco variables que se analizan en esta categoría: políticas de talento humano, herramientas para la evaluación de situaciones varias conducentes a la generación de valor y planes de fortalecimiento organizacional que apunten a la competencia global.

Figura 7. Categoría Posicionamiento.

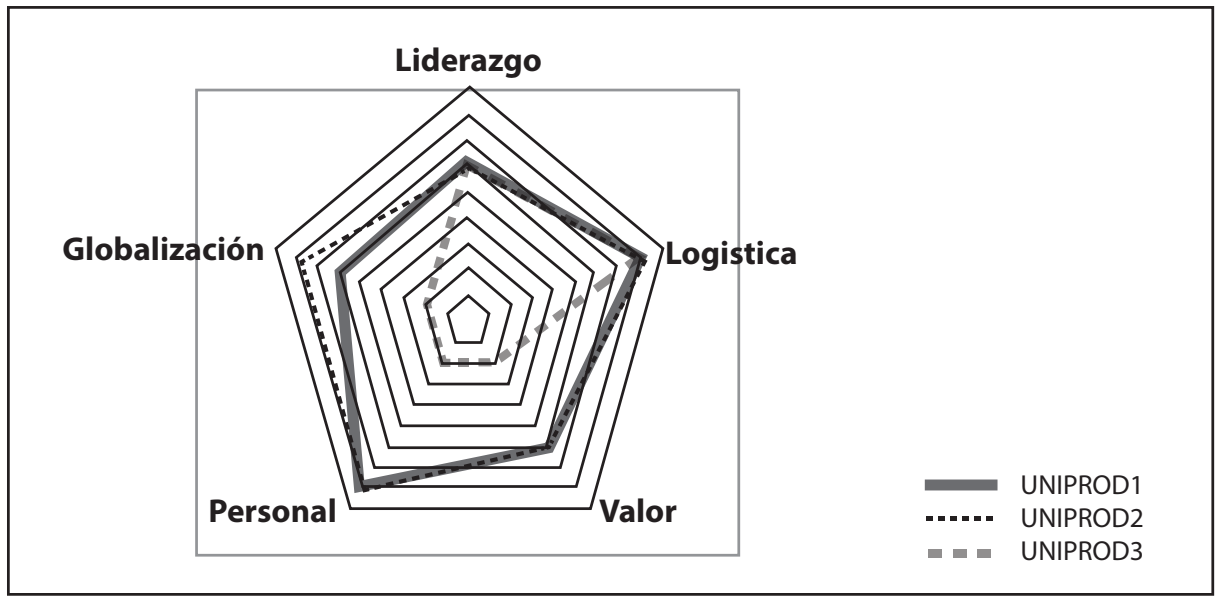

Fuente. Elaboración propia.

Las empresas UNIPROD1 y UNIPROD2, además de tener mayor desarrollo en los aspectos mencionados, tienen mejor definida su cadena logística, y presentan niveles de reconocimiento aceptables entre sus clientes actuales y potenciales. Es de rescatar la similitud en su percepción del posicionamiento, sobresaliendo un poco más en lo global la empresa UNIPROD2, cuya valoración coincide con su actual condición exportadora. 
La categoría Satisfacción al cliente solo se concluye a partir del análisis de tres variables, cuyo factor coincidente es la percepción que tienen las tres empresas respecto de la calidad. Sin embargo, solo la empresa UNIPROD2 demuestra por medio de procesos de certificación dicho desarrollo.

El menor desarrollo en las empresas de la provincia se presenta en la variable Servicios que incluye posventa, garantías, o sistemas de quejas y reclamos. El menor grado de desarrollo en esta categoría lo tiene la empresa UNIPROD3, que, además de los aspectos anteriores, manifestó poca posibilidad de competir con precio, y el desconocimiento de otros canales de comercialización, factores determinantes para impulsar el potencial competitivo a partir de esta categoría (figura 8).

Figura 8. Categoría Satisfacción al cliente

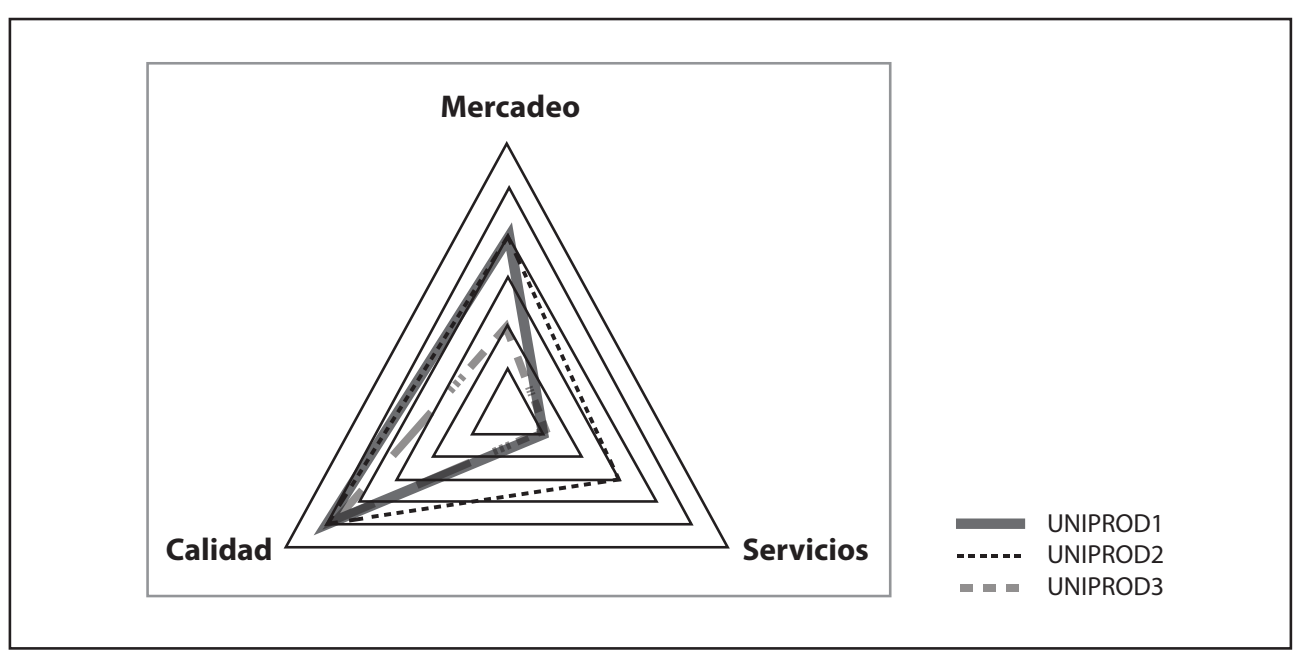

Fuente. Elaboración propia

La estrategia y su correspondiente planeación son actividades articuladoras de objetivos y metas, acordes con el modelo de negocios de cada firma y resultan de un proceso analítico conducente al desempeño superior. La categoría Planeación estratégica (figura 9) evidencia diferencias significativas entre las firmas, resaltando el grado «casi» óptimo de desarrollo de la empresa UNIPROD2. Las empresas UNIPROD1 y UNIPROD3 claramente no tienen un horizonte organizacional definido, resaltando su menor grado de desarrollo por la ausencia de misión y visión. 
Figura 9. Categoría Planeación estratégica

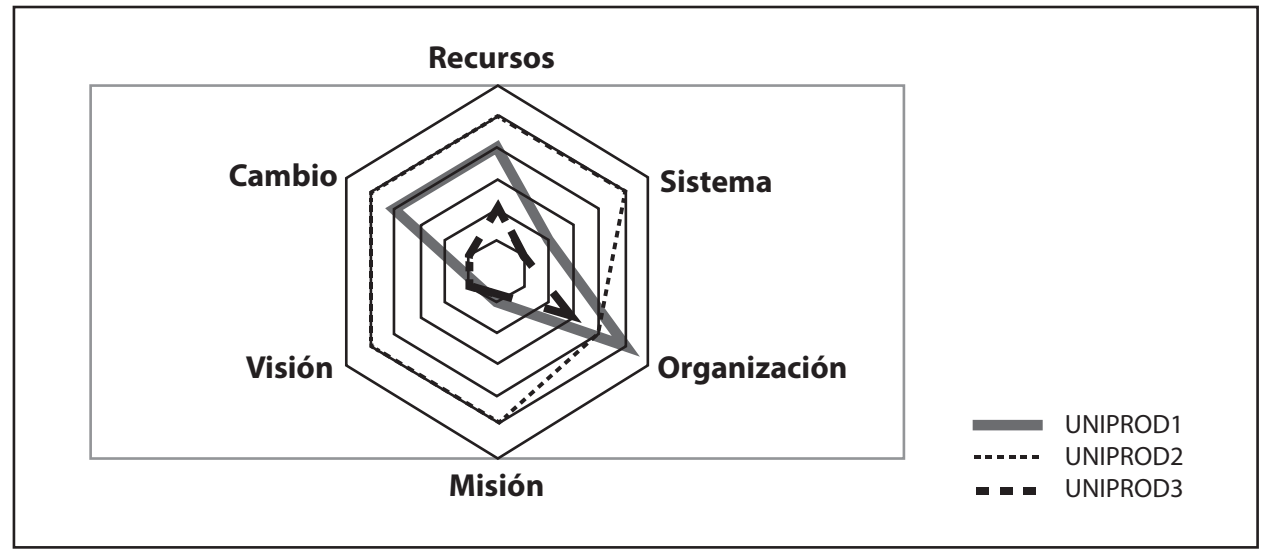

Fuente. Elaboración propia.

La comparación de las tres empresas con el uso del modelo deja ver que la empresa UNIPROD3 en las categorías analizadas siempre formaba los polígonos más pequeños, mientras que la empresa UNIPROD2 describe los polígonos de mayor tamaño. Esta evidencia empresarial es consistente con la premisa que señala que las empresas que se internacionalizan propenden a tener mayores desarrollos de sus potencialidades competitivas, frente a las empresas que se dedican a atender mercados locales. En un mundo cada vez más global, las empresas que se han dedicado solo a esto deben aprovechar sus oportunidades, orientar sus fortalezas y disminuir sus limitaciones so pena de ser castigadas por la competencia implacable del mercado.

En concordancia con la realidad empresarial, la empresa UNIPROD2 es la más grande en tamaño de las tres, y la única de ellas que actualmente realiza actividades de exportación, a pesar de llevar menos tiempo en el mercado. Lo anterior confirma que el método utilizado permite caracterizar potenciales competitivos para las empresas que se analicen, y que la posición competitiva de una firma es mejor cuando todos los componentes presentan altos niveles de desarrollo.

\subsection{Análisis cuantitativo}

La aproximación cuantitativa permite vislumbrar con mayor claridad los niveles de competitividad en las categorías de análisis utilizadas. La sencillez del cálculo es valorado como uno de los aportes más importantes de la propuesta, puesto que permite a mipymes hacer diagnóstico de su potencial competitivo. La valoración numérica se concreta en las áreas de los polígonos resultantes del análisis cualitativo, las cuales se obtienen de sumar las áreas de los triángulos internos de cada gráfico. En la tabla 5, se expresan las áreas calculadas como porcentajes de cumplimiento y se restan del porcentaje óptimo mostrando también porcentajes de desarrollo faltante para cada una de las categorías de análisis. La empresa UNIPROD1 destaca su desarrollo en las categorías de Infraestructura (70,93 \%), Evaluación financiera $(64,01 \%)$ y Toma de decisiones $(56,01 \%)$. Sus mayores oportunidades de mejora -desarrollo faltante del 78,64 \%- se encuentran en la categoría I+D. La empresa UNIPROD2 es la que presenta los porcentajes de desarrollo más altos al analizar el conjunto de las categorías. Su mayor fortaleza está en la categoría Planeación estratégica, y las mayores oportunidades están en la categoría 
I+D. La empresa UNIPROD3 no presenta ninguna categoría con un grado de desarrollo superior al $43 \%$, lo que la posiciona como la de menor potencial competitivo de las tres. Su mayor fortaleza está en la categoría Toma de decisiones $(42,01 \%)$, pero debe trabajar bastante en aspectos de planeación, estrategia, innovación y uso de la información financiera para la toma decisiones.

Tabla 5. Porcentaje de cumplimiento y porcentaje faltante de desarrollo de cada categoría de análisis respecto del desarrollo óptimo de potencial competitivo

\begin{tabular}{|c|c|c|c|c|c|c|}
\hline \multirow[b]{2}{*}{$\begin{array}{l}\text { Categoría de } \\
\text { análisis }\end{array}$} & \multicolumn{2}{|c|}{ UNIPROD1 } & \multicolumn{2}{|c|}{ UNIPROD2 } & \multicolumn{2}{|c|}{ UNIPROD3 } \\
\hline & $\begin{array}{c}\% \\
\text { cumplimiento } \\
\text { (área obtenida) }\end{array}$ & $\begin{array}{l}\% \text { faltante } \\
\text { (área } \\
\text { faltante) }\end{array}$ & $\begin{array}{c}\% \\
\text { cumplimiento } \\
\text { (área } \\
\text { completa) }\end{array}$ & $\begin{array}{l}\% \text { faltante } \\
\text { (área } \\
\text { reducida) }\end{array}$ & $\begin{array}{c}\% \\
\text { cumplimiento } \\
\text { (área } \\
\text { completa) }\end{array}$ & $\begin{array}{l}\% \text { faltante } \\
\text { (área } \\
\text { reducida) }\end{array}$ \\
\hline Vigilancia & 28,01 & 71,99 & 54,01 & 45,99 & 24,00 & 76,00 \\
\hline $\begin{array}{l}\text { Toma de } \\
\text { decisiones }\end{array}$ & 56,01 & 43,99 & 90,02 & 9,98 & 42,01 & 57,99 \\
\hline Infraestructura & 70,93 & 29,07 & 85,43 & 14,57 & 38,69 & 61,31 \\
\hline $\mathrm{I}+\mathrm{D}$ & 21,36 & 78,64 & 29,02 & 70,98 & 2,62 & 97,38 \\
\hline $\begin{array}{l}\text { Evaluación } \\
\text { financiera }\end{array}$ & 64,01 & 35,99 & 81,02 & 18,98 & 15,00 & 85,00 \\
\hline Posicionamiento & 45,94 & 54,06 & 51,58 & 48,42 & 16,93 & 83,07 \\
\hline $\begin{array}{l}\text { Satisfacción del } \\
\text { cliente }\end{array}$ & 43,10 & 56,90 & 69,84 & 30,16 & 20,80 & 79,20 \\
\hline $\begin{array}{l}\text { Planeación } \\
\text { estratégica }\end{array}$ & 29,55 & 70,45 & 94,03 & 5,97 & 8,73 & 91,27 \\
\hline
\end{tabular}

Nota: La suma del porcentaje de cumplimiento y el porcentaje faltante corresponde al nivel óptimo de desarrollo.

\section{Fuente. Elaboración propia.}

Se evidencia que la categoría con mayor distancia entre el nivel óptimo de desarrollo y el porcentaje de cumplimiento actual, en común para las tres empresas, es I+D. Existe en la provincia de Ubaté una baja inversión en $\mathrm{I}+\mathrm{D}$, pues no se considera una prioridad, al no verse resultados a corto plazo. Las empresas coinciden en priorizar el capital de trabajo, pues su apalancamiento financiero está concentrado en este rubro, y exigen demasiada «recompensa» por capitales que se destinen para otras labores no operativas. En este orden de ideas, es contradictorio el escenario, dado que manifiestan receptividad a las convocatorias que diversas instituciones realizan para capacitación y actualización, ${ }^{11}$ pero a la hora de invertir en investigación, actualización e innovación son escépticos y poco arriesgados.

Se resalta la categoría Infraestructura, pues se evidencian altos porcentajes de cumplimiento. La empresa UNIPROD1 obtuvo un 70,93\% de desarrollo, la empresa UNIPROD2 un 85,42 \% y la empresa UNIPROD3 un 38,69 \%, que, aunque es el más bajo respecto de las otras,

\footnotetext{
${ }^{11}$ En los últimos años, han recibido capacitaciones de diversas instituciones y empresas relacionadas con tecnologías de punta, mercadeo, aspectos sanitarios, buenas prácticas agrícolas, entre otros.
} 
es de los más altos porcentajes obtenidos por esta. Los productores locales se han preocupado por invertir bastante en este concepto, pero es claro luego del análisis cualitativo que el desarrollo de una sola categoría no potencia las posibilidades competitivas de una firma.

En general, la empresa con mayor grado de desarrollo en las categorías que determinan el potencial competitivo es la empresa UNIPROD2, lo que coincide con su posición comercial actual, las oportunidades que manifiesta de sus productos y la estabilidad de su sector. La empresa UNIPROD3 tiene «mucho por hacer» en pro de mejorar su potencial competitivo y elevar el nivel de desarrollo en cada una de las categorías, evidentemente, igual de importantes todas.

\section{Conclusiones y discusión}

El método aplicado presenta ventajas a la hora de determinar, desde un análisis endógeno y muy particular, las potencialidades competitivas de una empresa, comprobado en las tres firmas agroindustriales analizadas. Desde la realidad de las pymes del territorio, tener la posibilidad de calcular aspectos relacionados con sus potenciales competitivos se convierte en una herramienta práctica de análisis, planeación $\mathrm{y}$ toma de decisiones.

La validación del modelo con sus virtudes de sencillez, claridad y relativa autonomía hace de su aplicación una herramienta asequible a los microempresarios de la región estudiada y demuestra sus bondades para replicarlo en el estudio ampliado en otros sectores o regiones.

El acercamiento gráfico y numérico que proporciona el modelo deja una visión más clara del potencial competitivo de una empresa, sus avances o grados de desarrollo en las dimensiones más importantes. Su uso permite identificar con mayor claridad las oportunidades y los retos frente a los que tienen las empresas cuya «área resultante» se encuentra alejada de los niveles óptimos.

El análisis cuantitativo realizado distingue los factores que requieren mayor o menor desarrollo en cada componente, lo cual permite a cada empresa proyectar estrategias para mejorar su potencial competitivo. Además, estimula el planteamiento de nuevas investigaciones de la competitividad regional enfocado en criterios puntuales.

Otro hallazgo clave en el estudio, que representa un aporte significativo en los análisis de competitividad, está referido a que las tres empresas coinciden en la necesidad de hacer mayor I+D. En esta variable, las empresas deberían generar programas o proyectos que disminuyan la brecha existente entre situación real y condiciones ideales para el desarrollo de mayor competitividad apoyada en estas áreas. La provincia de Ubaté particularmente requiere fortalecimiento desde el punto de vista de la gestión empresarial enfocada en la definición de planes estratégicos y en la importancia de destinar recursos para I+D.

En las tres empresas analizadas, se logró un diagnóstico de competitividad a partir de las percepciones que tienen sus administradores de las categorías de análisis, por ejemplo, es preciso reconocer que la única que tiene definido un plan estratégico es la que tiene mayor potencial competitivo. Se validó el instrumento identificando características acordes con la realidad empresarial, evaluación de su 
potencial competitivo y de los aspectos que requieren más atención para incrementarlo.

Los resultados de la aplicación del modelo son consistentes con las apreciaciones de Guerras y Navas (2015), de tal manera que puede, incluso, al analizarse dos empresas del mismo sector, que sus resultados sean diferentes y por tanto sus potenciales competitivos distintos, pues la medición se realiza según las particularidades de las firmas, lo que les permite diseñar estrategias diferentes que respondan a las condiciones que les son propias.

Los análisis de competitividad empresarial aplicados proporcionan al sector agroindustrial de la provincia una visión amplia de los factores internos de las empresas que favorecen su incursión en mejores mercados y fortalecen su capacidad para sobrevivir en mercados globalizados. Además, amplían el espectro de las estrategias de intervención frente a la meta de incrementar la estabilidad económica local mediante el mejoramiento de los potenciales competitivos, que, si bien no dependen totalmente de los factores internos de las organizaciones, sí logran incrementar su eficiencia ante cambios positivos en las gestiones empresariales.

La aplicación del modelo de Sepúlveda et al. (2010) en la provincia de Ubaté ratifica los argumentos para asuntos de gestión. Se demuestra que los principales componentes que influyen en el potencial competitivo se relacionan con factores de forma, y evidencia que la conversión competitiva depende en gran medida tanto de la vigilancia como de la inversión en $\mathrm{I}+\mathrm{D}$.

Las condiciones de la evaluación autónoma de la competitividad pueden llevar a la trampa de excesiva subjetividad del analista de la empresa. De tal manera que el evaluador debe cumplir una condición de objetividad para no desdibujar la realidad con apreciaciones sobre o subvaloradas.

\section{Referencias}

Barker, T. y Köhler, J. (1998). Environmental policy and competitiveness. Environmental Policy Research Briefs, 6, 1-12.

Becerra Gualdrón, C. J. y Gallardo Sánchez, C.F. (2015). Competitividad de las empresas agroindustriales de Boyacá. Criterio Libre 13 (22), 227-252. Recuperado de http:// www.unilibre.edu.co/CriterioLibre/23/competitividad-de-las-empresas-agroindustriales-de-boyaca.pdf

Bobba, F., Langer, W. y Pous, J. (1971). Bericht über die Wettbewerbsfähigkeit der Europäischen. Brussels: Europäischen Gemeinschaft.

Buckley, P., Pass, C. y Prescott, K. (1988). Measures of international competitiveness: A critical survey. Journal of Marketing Management, 4(2), 175-200.
Cámara de Comercio de Bogotá. (s. f.). Bases de datos e información empresarial. Recuperado de https://www. ccb.org.co/Fortalezca-su-empresa/Temas-destacados/ Bases-de-datos-e-informacion-empresarial

Cámara de Comercio de Bogotá. (2013). Plan de Competitividad para la provincia de Ubaté. Bogotá: Cámara de Comercio de Bogotá.

Comisión Económica para América Latina y el Caribe. (1990). Transformación productiva con equidad. Santiago de Chile: Comisión Económica para América Latina y el Caribe. Recuperado de https://www.cepal.org/es/publicaciones/2102-transformacion-productiva-equidad-la-tarea-prioritaria-desarrollo-america-latina

Conpes 3439/2006, 14 de agosto, institucionalidad y principios rectores de política para la competitividad y productividad. 
Consejo Privado de Competitividad. (2016a). Índice Departamental de Competitividad 2016. Bogotá: Consejo Privado de Competitividad.

Consejo Privado de Competitividad. (2016b). Informe Nacional de Competitividad 2016-2017. Bogotá: Consejo Privado de Competitividad.

D'Andrea Tyson, L. (1992). Who's bashing whom? Trade conflict in high-technology industries. Washington, D. C.: Institute for International Economics.

Durán Lima, J. E. y Álvarez, M. (2008). Indicadores de comercio exterior y política comercial: mediciones de posición y dinamismo comercial. Santiago de Chile: Comisión Económica para América Latina y el Caribe. Recuperado de http:// repositorio.cepal.org/bitstream/handle/11362/3690/ S2008794_es.pdf

Esser, K., Wolfgang, H., Dirk, M. y Meyer-Stamer, J. (1996). Competitividad sistémica: nuevo desafío para las empresas y la política. Revista de la CEPAL, 59, 39-52.

Flejterski, S. (1984). Istota i mierzenie konkurencyjności międzynarodowej. Gospodarka Planowa, 9, 390-394.

Guerras Martín, L. Á. y Navas López, J. E. (2015). La dirección estratégica de la empresa: teoría y aplicaciones. Aranzadi.

Jiménez Ramírez, M. H. (2006). Modelo de competitividad empresarial. Umbral Científico, 9, 115-125.

Krugman, P. (1990). The age of diminished expectations. Cambridge: The MIT Press.

Krugman, P. (1994). Competitiveness: A Dangerous Obsession. Foreign Affairs, 73(2), 28-44.

Malassis, L. (1979). Economie Agro-alimentarie. París: Cujas.

Organización para la Cooperación y el Desarrollo Económicos. (1992). Technology and the economy: The key relationships. París: Organización para la Cooperación y el Desarrollo Económicos.

Porter, M. (1990). The competitive advantage of nations. Nueva York: The Free Press.

Porter, M. (1991). La ventaja competitiva de las naciones. México: Vergara.

Porter, M. (1999). Ventaja competitiva: crear y sostener un desempeño superior. México: Continental.

Porter, M. (2008). Las cinco fuerzas competitivas que le dan forma a la estrategia. Harvard Business Review, 86(1), 58-77.

Porter, M. y Rivkin, J. (2012). The Looming Challenge to U.S. Competitiveness. Harvard Business Review, 90(3), 54-61.

Porter, M. E., Ketels, C. y Delgado, M. (2007). The microeconomic foundations of prosperity: Findings from the business competitiveness index. En A. Lopez-Claros (ed.), The Global Competitiveness Report 2007-2008 (pp. 51-81). Basingstoke: Palgrave Macmillan.

Reta, M. (2008). Políticas para la competitividad. Pyme Hoy, 4, 31-59.

Rodríguez, Y., Rodríguez, C. \& Melo Perdomo, S. (2017). Análisis de competitividad para el portafolio de productos agroindustriales de la provincia de Ubaté (Cundinamarca-Colombia). En Memorias LI Asamblea Anual CLADEA 2016: "La innovación en las escuelas de negocio". Medellín: Asociación Colombiana de Facultades de Administración.

Romo Murillo, D. y Abdel Musik, G. (2005). Sobre el concepto de competitividad. Revista Comercio Exterior, $55(3)$.

Rubio Bañón, A. y Aragón Sánchez, A. (2008). Recursos estratégicos en la pymes. Revista Europea de Dirección y Economía de la Empresa, 17(1), 103-126.

Schwab, K. y Sala-i Martin, X. (2013). The Global Competitiveness Report 2013-2014. Ginebra: World Economic Forum.

Scott, B. R. y Lodge, G. C. (1985). US competitiveness in the world economy. The International Executive, 27(1), 26-26.

Sepúlveda, J. D., Meriño, L. I., Del Río, J. L. y García, A. (2010). Metodología para la evaluación del potencial competitiva en pequeñas y medianas empresas basado en el esquema de capacidades internas. Revista Internacional Administración \& Finanzas, 3(1), 97-107.

Siudek, T. y Zawojska, A. (2014). Competitiveness in the economic concepts, theories and empirical research. Acta Scientiarum Polonorum, Oeconomía, 13(1), 91-108. Recuperado de http://yadda.icm.edu.pl/yadda/ element/bwmeta1.element.agro-b3b94eea-5c1c4805-9a76-c82799727548

Solleiro, J. y Castañón, R. (2005). Competitiveness and innovation systems: The challenges for Mexico's insertion in the global context. Technovation, 45, 1059-1070.

Suñol, S. (2006). Aspectos teóricos de la competitividad. Ciencia y Sociedad, 31(2), 179-198. Recuperado de http://www. redalyc.org/pdf/870/87031202.pdf

Wang, C. H. y Hsu, L. C. (2010). The influence of dynamic capability on performance in the high technology industry: The moderating roles of governance and competitive posture. African Journal of Business Management, 4(5), 562-577. 


\section{Anexo A: Matriz categorías de análisis, variables y criterios de evaluación}

\begin{tabular}{|c|c|c|}
\hline $\begin{array}{l}\text { Categoría de } \\
\text { análisis }\end{array}$ & Variable & Criterios por tener en cuenta en el análisis de cada variable \\
\hline Vigilancia & $\begin{array}{l}\text { Búsqueda } \\
\text { Análisis } \\
\text { Fuente } \\
\text { Conocimiento }\end{array}$ & $\begin{array}{l}\text { La empresa realiza periódicamente un proceso de búsqueda de información y vi- } \\
\text { gilancia de sus competidores, su entorno y los elementos que podrían afectarla. } \\
\text { Existe personal responsable del análisis de la información derivada del proceso de } \\
\text { vigilancia. } \\
\text { La empresa utiliza para el análisis de la información la totalidad de las siguientes } \\
\text { fuentes: } \\
\text { internet, patentes, estudios sectoriales, boletines técnicos, boletines científicos. } \\
\text { Se generan y discuten en comité informes de resultados del proceso de vigilancia y } \\
\text { estos conducen a la toma de decisiones sobre el negocio. }\end{array}$ \\
\hline $\begin{array}{l}\text { Toma de } \\
\text { decisiones }\end{array}$ & $\begin{array}{l}\text { Bases (técnicas) } \\
\text { Claves } \\
\text { Experiencia } \\
\text { Propiedad }\end{array}$ & $\begin{array}{l}\text { La toma de decisiones corresponde a un proceso técnico de análisis de datos e in- } \\
\text { formación relevante y no a un proceso basado en mitos y creencias de las directivas. } \\
\text { Se conocen y se evalúan periódicamente los factores claves de desempeño del ne- } \\
\text { gocio. } \\
\text { El personal involucrado en la toma de decisiones ha estado inmerso en el negocio y } \\
\text { ha recibido formación relacionada con este durante los últimos cinco años. } \\
\text { Cada persona en la organización conoce y aplica sus alcances y limitaciones en el } \\
\text { proceso de toma de decisiones. }\end{array}$ \\
\hline Infraestructura & $\begin{array}{l}\text { Condiciona- } \\
\text { miento } \\
\text { Aprovechamiento } \\
\text { Mejoras }\end{array}$ & $\begin{array}{l}\text { Existe en la organización una política clara relacionada con la infraestructura y el } \\
\text { mantenimiento de la planta física y equipos y además esta está de acuerdo con las } \\
\text { normas legales que rigen el sector. } \\
\text { Se conocen los beneficios de la infraestructura actual en cuanto a los siguientes } \\
\text { aspectos: cercanía a los mercados, facilidades de acceso, cercanía y facilidades con } \\
\text { los proveedores, costos y ventajas intangibles. } \\
\text { Las condiciones de operación de la planta física y los equipos de trabajo están de } \\
\text { acuerdo con los parámetros legales vigentes. } \\
\text { Se explotan económica y comercialmente los beneficios de la infraestructura actual } \\
\text { en cuanto a los siguientes aspectos: cercanía a los mercados, facilidades de acceso, } \\
\text { cercanía y facilidades con los proveedores, costos, ventajas intangibles. } \\
\text { Existe un plan periódico de mantenimiento, adecuación, expansión y mejora de la } \\
\text { planta física y equipos de trabajo y además se cuenta con el capital para su ejecu- } \\
\text { ción. }\end{array}$ \\
\hline $\mathrm{I}+\mathrm{D}$ & $\begin{array}{l}\text { Capital } \\
\text { Objetivos } \\
\text { Encadenamiento } \\
\text { Capacidades }\end{array}$ & $\begin{array}{l}\text { Existe en la organización una asignación económica para los procesos de investi- } \\
\text { gación e innovación. } \\
\text { Existe una política y se evalúa periódicamente respecto de los cambios en pro- } \\
\text { ductos y procesos y estos no obedecen a simples requerimientos del mercado y } \\
\text { oportunidades esporádicas de acción. } \\
\text { En los procesos de investigación y desarrollo de nuevos productos y servicios, se } \\
\text { conocen y establecen acuerdos de cooperación con los siguientes actores: univer- } \\
\text { sidades y centros de desarrollo tecnológico, competidores, proveedores y clientes, } \\
\text { consultores especializados. } \\
\text { Existe en la organización una base de datos que involucra las competencias indivi- } \\
\text { duales del personal y sus capacidades en el proceso de investigación y desarrollo de } \\
\text { nuevos o mejorados productos y procesos. } \\
\text { La empresa cuenta con los siguientes recursos relacionados con TIC y los explota: } \\
\text { internet banda ancha y planes de telefonía celular nacional e internacional, bases de } \\
\text { datos e información especializada, programas de seguridad informática, paquetes } \\
\text { básicos de procesamiento de datos e información y programas especializados para } \\
\text { diseño y gestión de acuerdo con las tendencias del sector. }\end{array}$ \\
\hline
\end{tabular}




\begin{tabular}{|c|c|c|}
\hline & Seguimiento & $\begin{array}{l}\text { Existe una metodología de evaluación y toma de decisiones basada en el análisis de } \\
\text { los estados financieros que cumple con las siguientes condiciones: es aplicada pe- } \\
\text { riódicamente, involucra personal de diferentes niveles en su análisis, la evaluación } \\
\text { implica conceptos de análisis financiero actual. } \\
\text { El análisis financiero es una herramienta de apoyo a la toma de decisiones que } \\
\text { involucra un proceso constante de capacitación en estos aspectos de manera que el } \\
\text { proceso se encuentra al día con las tendencias de evaluación financieras globales. } \\
\text { Se realiza un seguimiento constante a los estados financieros y los resultados de los } \\
\text { ejercicios contables mediante indicadores y tecnología y el personal tiene acceso a } \\
\text { estos de manera que pueda participar en el proceso. } \\
\text { La empresa ha tenido resultados financieros positivos y cuenta con recursos para } \\
\text { inversión y mejoramiento continuo. }\end{array}$ \\
\hline Posicionamiento & $\begin{array}{l}\text { Liderazgo } \\
\text { Logística } \\
\text { Valor } \\
\text { Personal }\end{array}$ & $\begin{array}{l}\text { La empresa es reconocida por los clientes potenciales y su imagen es positiva. } \\
\text { Existe un proceso de encadenamiento logístico con clientes y proveedores que per- } \\
\text { mite obtener ventajas competitivas frente a otros competidores. } \\
\text { Existe una metodología para la evaluación de valor y se conocen las actividades } \\
\text { generadoras de este dentro de la organización y además estas son aplicadas. } \\
\text { El personal de la organización cuenta con las siguientes características: posee la } \\
\text { formación necesaria para sus labores, tiene acceso a cursos y programas de forma- } \\
\text { ción y actualización brindados por la organización, posee un contrato de acuerdo } \\
\text { con sus capacidades y la remuneración se encuentra al menos en el promedio del } \\
\text { sector, conoce sus tareas y responsabilidades y estas están consignadas en un ma- } \\
\text { nual de funciones o perfil de competencias, es tratado según su condición de ser } \\
\text { humano y en igualdad de condiciones frente a sus superiores y subalternos. } \\
\text { La empresa conoce sus limitaciones y fortalezas frente a la competencia global y ha } \\
\text { establecido planes periódicos de fortalecimiento organizacional, técnico, tecnoló- } \\
\text { gico y frente a ellos. }\end{array}$ \\
\hline $\begin{array}{l}\text { Satisfacción del } \\
\text { cliente }\end{array}$ & Mercadeo & $\begin{array}{l}\text { Se conocen y utilizan los diferentes canales de acceso a los clientes y la información } \\
\text { respecto de ellos permanece actualizada, además es posible competir en precio, } \\
\text { captar nuevos clientes de la competencia, existe un proceso de fidelización de clien- } \\
\text { tes. } \\
\text { Existe un proceso de valor agregado a los productos y servicios ofertados mediante } \\
\text { una estrategia de servicio que incluye sistema de comunicación de quejas y recla- } \\
\text { mos, seguimiento permanente a las indicaciones y los requerimientos de los clien- } \\
\text { tes, garantía y servicio posventa. } \\
\text { Existe un proceso para la medición y el aseguramiento de la calidad de los produc- } \\
\text { tos y servicios ofertados que involucra sistema de control estadístico de la calidad, } \\
\text { de gestión de la calidad (en operación, no necesariamente asegurado), seguimiento } \\
\text { de quejas, reclamos y requerimientos de los clientes, plan de mejora de la calidad, } \\
\text { conocimiento y aplicación de los estándares de calidad establecidos legalmente. }\end{array}$ \\
\hline $\begin{array}{l}\text { Planeación } \\
\text { estratégica }\end{array}$ & $\begin{array}{l}\text { Recursos } \\
\text { Sistema } \\
\text { Organización }\end{array}$ & $\begin{array}{l}\text { La empresa conoce y explota los diferentes recursos y talento humano disponibles } \\
\text { para el logro de sus objetivos estratégicos. } \\
\text { Existe un sistema de planeación que involucra al personal en todos los niveles de } \\
\text { la organización. } \\
\text { El modelo organizacional está acorde con las tendencias del sector a nivel regional, } \\
\text { nacional e internacional. } \\
\text { La misión de la organización permite la expansión del negocio dentro del sector y } \\
\text { al mismo tiempo marca un camino que involucra los siguientes aspectos: tecnolo- } \\
\text { gía, talento humano, conocimiento del sector y la industria, tendencias globales, } \\
\text { sinceridad en los postulados. } \\
\text { La visión de la organización está presente en los objetivos estratégicos. } \\
\text { La estructura organizacional, el modelo directivo y la actitud de los empleados per- } \\
\text { miten una eventual disposición positiva frente a cambios en el entorno. }\end{array}$ \\
\hline
\end{tabular}

Fuente. Sepúlveda, Meriño, Del Río y García, 2010. 